\title{
FITOTECNIA
}

\section{ANÁlISE ECONÔMICA COMPARATIVA APÓS UM ANO DE CULTIVO DO FEIJOEIRO IRRIGADO, NO INVERNO, EM SISTEMAS DE PLANTIO CONVENCIONAL E DIRETO, COM DIFERENTES FONTES E DOSES DE NITROGÊNIO(1)}

\author{
ROSALINA MARIA ALVES RAPASSI ${ }^{(2)}$; MARCO EUSTÁQUIO DE SÁ ${ }^{(3)}$; \\ MARIA APARECIDA ANSELMO TARSITANO(3); MARCO ANTONIO CAMILLO DE CARVALHO ${ }^{(3)}$; \\ ÉRCIO ROBERTO PROENÇA ${ }^{(3)}$; CÉLIA MATILDE TEGON DE CASTRO NEVES ${ }^{(4)}$; \\ EDGAR CARLOS MARTINS COLOMBO(5)
}

\begin{abstract}
RESUMO
Realizou-se a análise comparativa de custos de produção de feijão, após um ano em sistemas de plantio direto e convencional, no período de inverno, com irrigação por pivô central. Os experimentos foram desenvolvidos na Fazenda Dois Irmãos, em Pereira Barreto (SP), em delineamento experimental de blocos ao acaso, com 11 tratamentos e quatro repetições, para cada sistema de plantio. Os tratamentos constaram de uma testemunha sem $\mathrm{N}$, duas fontes de $\mathrm{N}$ (uréia e nitrato de amônio) e cinco dosagens $\left(20,40,60,80\right.$ e $\left.100 \mathrm{~kg} \cdot \mathrm{ha}^{-1} \mathrm{de} \mathrm{N}\right)$, aplicados em cobertura aos 27 dias após a emergência das plantas. Utilizou-se densidade de 15 plantas por metro de linha e 0,50 m entre sulcos, com semeadura realizada em 20/5/2001. Na área do sistema de plantio direto, as plantas daninhas foram dessecadas após o cultivo do milho, e na de plantio convencional, realizaram uma aração e duas gradagens, sendo uma pesada e uma niveladora, no preparo do solo. Durante o desenvolvimento da cultura foram aplicados herbicidas em pós-emergência para o controle do mato. As duas fontes de nitrogênio mostraram efeito positivo na produção de grãos. A análise econômica revelou melhor resultado para uréia, na dose de $60 \mathrm{~kg}$.ha- ${ }^{-1}$ de $\mathrm{N}$, em preparo convencional do solo, com índice de lucratividade de $40,6 \%$. Para o plantio direto, o nitrato de amônio, na base de $40 \mathrm{~kg} \cdot \mathrm{ha}^{-1}$ de $\mathrm{N}$, mostrou maior acréscimo na receita e lucratividade de $25,6 \%$.
\end{abstract}

Palavras-chave: Phaseolus vulgaris, custo de produção, nitrogênio, preparo do solo, plantio direto, adubação.

\begin{abstract}
FIRST YEAR COMPARATIVE ECONOMIC ANALYSIS OF BEAN CROP AT CONVENTIONAL AND NO-TILLAGE SYSTEMS, UNDER DIFFERENT AMMOUNTS AND SOURCES OF NITROGEN

A comparative economical evaluation of conventional and no-tillage bean crop systems was done. A field experiment was settled under irrigation, at Dois Irmãos Farm, Pereira Barreto, São Paulo State, sowed in the winter of 2001. The experimental design was a randomized block with four replications for
\end{abstract}

( $\left.{ }^{1}\right)$ Recebido para publicação em 19 de fevereiro de 2002 e aceito em 14 de julho de 2003.

(2) Mestrando em Agronomia, FE/UNESP - Ilha Solteira (SP). E-mail: rapassi@clubinter.com.br

$\left({ }^{3}\right)$ Departamento de Fitotecnia e Economia e Sociologia Rural, FEIS/UNESP, Caixa Postal 31, 15385-000 Ilha Solteira (SP), Brasil.

$\left({ }^{4}\right)$ Coordenadoria de Defesa Agropecuária do Estado de São Paulo Av. Gerônimo Gonçalves, 64, 14010-040 Ribeirão Preto (SP). E-mail edariberao@cda.sp.gov.br

$\left({ }^{5}\right)$ Faculdades Integradas Urubupungá - Av. Jonas Alves de Melo, 1660, 15370-000 Pereira Barreto (SP). E-mail: fiu@fiu.br 
each tillage system. $\mathrm{N}$ fertilization was applied 27 days after emergency at the rates of 20, 40, 60, 80, 100 $\mathrm{kg} \cdot \mathrm{ha}^{-1}$ of $\mathrm{N}$. Urea and ammonium nitrate were used as nitrogen source. The cv. Carioca was used at a seed density of 15 seeds per meter in rows $0,50 \mathrm{~cm}$ apart. Herbicide was applied in the no-tillage plots before sowing. Conventional tillage plots were prepared with plowing and harrowing twice. The results show that bean crop responds differently the nitrogen source. The economical evaluation pointed out the higher profitable index of $40,6 \%$ for urea source at $\mathrm{N}$ doses of $60 \mathrm{~kg}$.ha ${ }^{-1}$, under conventional tillage system. The best result for no tillage sowed $25,6 \%$ profitable index and was obtained with $40 \mathrm{~kg} \cdot \mathrm{ha}^{-1}$ of $\mathrm{N}$.

Key words: Phaseolus vulgaris, economical evaluation, $\mathrm{N}$ fertilization.

\section{INTRODUÇÃO}

A cultura do feijoeiro vem mantendo há muitos anos um importante lugar na agricultura brasileira, tendo em vista, principalmente, grande uso na alimentação, com consumo médio de $2.950 \mathrm{mil} \mathrm{t}$ /ano ou $18 \mathrm{~kg}$ por habitante/ano.

A produção brasileira de feijão, estimada em 2000/2001 pela CONAB (2001), foi de $2.909,6$ mil toneladas, com redução de $6 \%$ em relação à safra anterior. Os Estados do Paraná e de Minas Gerais se destacaram na produção de feijão das águas (1. ${ }^{a}$ safra), representando $40 \%$ da produção total; Bahia, Minas Gerais e Ceará, na produção de feijão da seca (2. ${ }^{a}$ safra), com $52 \%$ da produção total nacional e São Paulo, Goiás e Minas Gerais, na safra de inverno, mas com baixa participação na produção total - cerca de $8 \%$. Não obstante, essa baixa participação equivale a uma produtividade de $1.545 \mathrm{~kg} \cdot \mathrm{ha}^{-1}$, o dobro das médias obtidas nas duas outras safras, que foram $761 \mathrm{e}$ $785 \mathrm{~kg} . \mathrm{ha}^{-1}$ respectivamente.

A grande variação na oferta de feijão influencia os preços recebidos pelos produtores no Estado de São Paulo, onde são estabelecidos os preços indicadores como referência no restante do País.

Como em 2000 houve redução de 21,6\% na área plantada da $1 .^{a}$ safra em relação à anterior, a produção foi comercializada com preços melhores que os recebidos no ano anterior - em média $R \$ 60,00$ por saca (KIYUNA, 2001).

A cultura do feijoeiro apresenta baixos níveis médios de produtividade, e fatores como tipo de cultivares, baixa tecnologia de cultivo, uso reduzido de insumos e a ocorrência de pragas e doenças têm sido citados como limitantes ao seu adequado desempenho.

Na safra de inverno, a produção se dá com o uso mais intenso de tecnologia, representada por cultivares específicas, irrigação, manejo de solos e controle de pragas e doenças. A importância da terceira safra está, não apenas na maior estabilidade de mercado, mas também na mudança do perfil do produtor, apesar da baixa representatividade na produção total (NeHMI et al, 2000).
O fornecimento de nutrientes para essa cultura é de suma importância, sendo o nitrogênio o elemento mais absorvido pelas plantas. Embora a planta apresente a fixação simbiótica do nutriente, muitas vezes esse fato não tem sido efetivo para proporcionar elevados níveis de produtividade. Citando Malavolta (1987), enquanto a soja consegue fixar $40 \%$ a $70 \%$ do nitrogênio necessário nos nódulos, o feijoeiro fixa bem menos, entre $20 \%$ e $30 \%$. Assim, é imprescindível a aplicação de nitrogênio nessa cultura para que a produção não seja afetada negativamente pela sua falta.

Uma das alternativas de cultivo do feijoeiro visando diminuir os problemas na cultura, além dos cuidados com a adubação, é o sistema de plantio direto.

O plantio direto pode influenciar a temperatura do solo. Nos trabalhos de Moreira e StONe (1995), constatou-se que, durante parte do período vegetativo do feijoeiro, a temperatura medida na superfície do solo foi sempre menor no plantio direto. Nesse sistema, promovem-se a diminuição da evaporação e a maior capacidade de armazenamento da água da chuva, no perfil do solo (Blevins et al., citados por BALBINO et al. 1996).

Neste trabalho, analisou-se economicamente a produção de feijão irrigado de inverno, na região de Pereira Barreto (SP), considerando-se duas fontes alternativas de nitrogênio, em diferentes dosagens, nos sistemas de plantio direto e convencional.

\section{MATERIAL E MÉTODOS}

Os experimentos foram instalados na Fazenda Dois Irmãos, no município de Pereira Barreto, na Região Noroeste do Estado de São Paulo, em Latossolo Vermelho-Escuro. As características químicas do solo foram determinadas antes da instalação dos experimentos, em análises realizadas no Laboratório de Fertilidade do Solo e Nutrição de Plantas, da Faculdade de Engenharia/UNESP, do Campus de Ilha Solteira (SP). Na camada de $0-20 \mathrm{~cm}$ obtiveram-se os valores de $\mathrm{pH}(\mathrm{CaCl2}): 5,9$; M.O.: 19 g. $\mathrm{dm}^{-3}$; P resina: $61 \mathrm{~g} \cdot \mathrm{dm}^{-3}$; em mmol $\mathrm{dm}^{-3}$ para $\mathrm{K}: 4,2$; Ca: 38 ; $\mathrm{Mg}$ : 6; H+AL: 15; SB: 49; V: 76\%. 
Na semeadura, utilizou-se o espaçamento de 0,50 m entre linhas, com 15 sementes por metro de sulco, com o objetivo de se obter, posteriormente, uma população de aproximadamente 240.000 plantas por hectare. O delineamento experimental foi o de blocos ao acaso, com quatro repetições. As sementes foram tratadas com Carboxin 0,25 L/100 kg e Carbosulfan $0,62 \mathrm{~kg} / 100 \mathrm{~kg}$, visando à proteção contra pragas e agentes fitopatogênicos do solo.

A adubação química básica, colocada no sulco de semeadura, constou de $420 \mathrm{~kg}$.ha ${ }^{-1}$ da formulação 04-30-10 + Zn. A adubação nitrogenada em cobertura foi realizada aos 27 dias após a emergência das plantas, adotando-se como fontes de $\mathrm{N}$ a uréia ( $44 \%$ de $\mathrm{N}$ ) e o nitrato de amônio ( $32 \%$ de $\mathrm{N}$ ), nas doses de 0,20 , 40, 60, 80, 100 kg.ha ${ }^{-1}$ de nitrogênio, além de um tratamento-testemunha, sem aplicação de $\mathrm{N}$.

Cada parcela constou de seis linhas de $5 \mathrm{~m}$ de comprimento. Considerou-se como área útil as quatro linhas centrais, desconsiderando-se $0,5 \mathrm{~m}$ em cada extremidade, perfazendo $10 \mathrm{~m}^{2}$ para cada parcela.

Durante o desenvolvimento da cultura, foram realizados os tratos culturais e fitossanitários normalmente recomendados para o feijão de inverno.

Aplicou-se o inseticida methamidophós, na dose de 1 L.ha $^{-1}$ p.c., em três aplicações, para o controle de vaquinhas (Diabrotica speciosa e Cerotoma arcuata), cigarrinha verde (Empoasca kraemeri) e mosca-branca (Bemisia tabaci), e o acaricida triazophos, na dose de 1 L.ha $^{-1}$ p.c., em duas aplicações, para o controle de ácaro branco (Polyphagotarsonemus latus) e da larva minadora (Liriomysa spp). Em todas as aplicações, utilizou-se 400 L.ha $^{-1}$ de calda, para boa cobertura das plantas. Para o controle das doenças, aplicou-se, em três pulverizações, juntamente com o inseticida, o fungicida mancozeb, na dose de $2 \mathrm{~kg} \cdot \mathrm{ha}^{-1}$ do p.c.

No sistema de plantio direto, a cultura anterior ao feijoeiro foi o milho. Assim, na palhada, antes da semeadura da leguminosa, foram aplicados herbicidas para dessecação das plantas daninhas existentes na área, tais como corda-de-viola (Ipomoea sp), beldroega (Portulaca oleracea), trapoeraba (Commelina bengalensis), capim pé-de-galinha (Eleusine indica), capim-arroz (Echinochloa crusgalli), leiteiro (Euphorbia heterophylla), colonião (Panicum maximum), capim carrapicho (Cenchrus echinatus), caruru (Amaranthus sp), poaia branca (Richardia brasiliensis), guanxuma (Sida $s p$ ) e serralha (Sonchus oleraceus). Aplicou-se o herbicida glyphosate, na dose de 1,44 kg.ha- ${ }^{-1}$ i.a. e, posteriormente, o paraquat, na dose de $0,5 \mathrm{~kg}^{-\mathrm{ha}^{-1}}$ i.a. e $2-4 \mathrm{D}$, na dose de $1 \mathrm{~kg}$ ha $^{-1}$ i.a., para dessecação das plantas daninhas remanescentes na área. Aos dez dias após a aplicação de 2-4D, em 20/5/2001, foi realizada a semeadura do feijão, cultivar Carioca. Para o controle das plantas daninhas em pós-emergência foram aplicados os herbicidas bentazon $\left(0,72 \mathrm{~kg} \mathrm{ha}^{-1}\right.$ i.a.) + fenoxaprop-p-etil $\left(0,110 \mathrm{~kg}\right.$.ha ${ }^{-1}$ i.a. $)$ e fomesafem $(0,125 \mathrm{~kg}$.ha i.a.), aplicados na forma de mistura antes do florescimento do feijoeiro.

No sistema de plantio convencional, o solo foi preparado por uma aração e duas gradagens, uma pesada e uma niveladora.

O método de custo utilizado no presente trabalho foi o do sistema de Custo Operacional Total, do Instituto de Economia Agrícola, proposto por Matsunaga et al.(1976). Para determinar o lucro da atividade foram estimados, para cada tratamento, os seguintes indicadores: receita bruta, obtida pelo produto da quantidade obtida (em sacas) pelo preço médio da saca de feijão, recebida pelo produtor em setembro de 2001 ( $R \$ 55,00 / \mathrm{sc}$ de $60 \mathrm{~kg}$ ); o lucro operacional, calculado pela diferença entre a receita bruta e o custo operacional total; e o índice de lucratividade, representado pela relação entre o lucro operacional e a receita bruta em termos percentuais.

Os dados relativos aos coeficientes técnicos e à produtividade, utilizados no cálculo dos custos de produção e de lucratividade, foram obtidos no campo e também por técnicos da região. Os preços dos insumos e do produto referem-se aos pagos e recebidos pelos produtores na região em setembro de 2001. Todas as atividades foram acompanhadas e quantificadas, desde o preparo do solo (dessecação) até a colheita e secagem dos grãos (13\% de umidade).

\section{RESULTADOS E DISCUSSÃO}

O quadro 1 apresenta, por hectare, as estimativas de produção, custos e lucratividade, por tratamento, da cultura do feijoeiro nos sistemas de plantio direto e convencional. Verifica-se que o custo operacional total variou de $\mathrm{R} \$ 1.061,70$ (quando não se aplicou N) a R $1.200,70$ (para $100 \mathrm{~kg}$ de $\mathrm{N}$ do nitrato de amônio) em função das diferentes fontes e doses de nitrogênio; a produção variou de 20,30 sacas (20 kg de $\mathrm{N}$ do nitrato de amônio) a 27,33 sacas por hectare (40 kg de $\mathrm{N}$ do nitrato de amônio), para o plantio direto. Para o sistema de plantio convencional, o custo operacional variou de $\mathrm{R} \$ 945,75$ (quando se aplicou 0 de N) a R $\$ 1.085,75$ (para 100 $\mathrm{kg}$ de $\mathrm{N}$ do nitrato de amônio) em vista das diferentes fontes e doses de nitrogênio; a produção variou de 26,72 sacas ( $60 \mathrm{~kg} \cdot \mathrm{ha}^{-1}$ de $\mathrm{N}$ de nitrato de amônio) a 31,17 sacas por hectare (60 kg.ha ${ }^{-1}$ de $\mathrm{N}$ de uréia). 
Quadro 1. Estimativa do custo de produção, receita bruta e lucratividade em função das doses de nitrogênio na cultura de inverno de feijão irrigado, plantio convencional e plantio direto, em Pereira Barreto (SP), setembro de 2001

\begin{tabular}{|c|c|c|c|c|c|c|c|c|c|c|c|}
\hline \multirow[t]{2}{*}{ Fonte } & \multirow[t]{2}{*}{ Doses de $\mathrm{N}$} & \multicolumn{2}{|c|}{ Produtividade } & \multicolumn{2}{|c|}{ Custo operacional } & \multicolumn{2}{|c|}{ Receita bruta } & \multicolumn{2}{|c|}{ Lucro operacional } & \multicolumn{2}{|c|}{$\begin{array}{c}\text { Índice de } \\
\text { lucratividade }\end{array}$} \\
\hline & & P.C. & P.D. & P.C. & P.D. & P.C. & P.D. & P.C. & P.D. & P.C. & P.D. \\
\hline & $\mathrm{kg} \cdot \mathrm{ha}^{-1}$ & \multicolumn{2}{|c|}{$\mathrm{sc} / \mathrm{ha}$} & \multicolumn{6}{|c|}{$\mathrm{R} \$ /$ ha } & \multicolumn{2}{|c|}{ 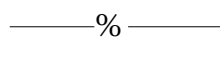 } \\
\hline \multirow[t]{6}{*}{ Uréia } & 0 & $26,28 \mathrm{a}$ & $21,50 \mathrm{a}$ & 945,7 & $1.061,7$ & $1.445,4$ & $1.182,5$ & 499,6 & 120,8 & 34,6 & 10,2 \\
\hline & 20 & $28,57 \mathrm{a}$ & $22,32 a$ & 969,7 & $1.085,7$ & $1.571,3$ & $1.227,6$ & 601,6 & 141,9 & 38,3 & 11,6 \\
\hline & 40 & $28,23 a$ & $22,64 \mathrm{a}$ & 993,7 & $1.109,7$ & $1.552,6$ & $1.245,0$ & 558,9 & 144,3 & 36,0 & 11,6 \\
\hline & 60 & $31,17 a$ & $23,54 a$ & $1.017,7$ & $1.133,7$ & $1.714,3$ & $1.294,7$ & 696,6 & 161,0 & 40,6 & 12,4 \\
\hline & 80 & $28,87 a$ & $25,14 a$ & $1.041,7$ & $1.157,7$ & $1.587,8$ & $1.382,7$ & 546,1 & 225,0 & 34,4 & 16,3 \\
\hline & 100 & $27,45 a$ & $24,46 a$ & $1.065,7$ & $1.181,7$ & $1.509,7$ & $1.345,2$ & 444,0 & 163,5 & 29,4 & 12,2 \\
\hline \multirow[t]{6}{*}{ Nitrato de Amônio } & 0 & $26,88 \mathrm{a}$ & $21,50 \mathrm{a}$ & 945,7 & $1.061,7$ & $1.445,4$ & $1.182,5$ & 499,6 & 120,8 & 34,6 & 10,2 \\
\hline & 20 & $27,88 \mathrm{a}$ & $20,30 \mathrm{a}$ & 973,7 & $1.089,7$ & $1.533,4$ & 116,5 & 559,6 & 26,8 & 36,5 & 2,4 \\
\hline & 40 & $28,38 \mathrm{a}$ & $27,33 a$ & $1.001,7$ & $1.117,7$ & $1.560,9$ & $1.503,1$ & 559,1 & 385,4 & 35,8 & 25,6 \\
\hline & 60 & $26,72 a$ & $24,45 a$ & $1.029,7$ & $1.145,7$ & $1.469,6$ & $1.344,7$ & 439,9 & 199,0 & 29,9 & 14,8 \\
\hline & 80 & $28,42 \mathrm{a}$ & $23,92 a$ & $1.057,7$ & $1.173,7$ & $1.563,1$ & $1.315,6$ & 505,3 & 141,6 & 32,3 & 10,8 \\
\hline & 100 & $30,41 \mathrm{a}$ & $26,77 a$ & $1.085,7$ & $1.200,7$ & $1.672,5$ & $1.472,3$ & 586,8 & 271,6 & 35,1 & 18,5 \\
\hline C.V. (\%) & & 15,04 & 15,61 & & & & & & & & \\
\hline
\end{tabular}

PC: Plantio convencional e PD: Plantio direto. sc/ha: $60 \mathrm{~kg}$. 
Conforme os resultados do quadro 2, estão evidenciadas as diferenças da resposta ao tipo de adubo quando se comparam os efeitos do nitrato de amônio e da uréia na produtividade do feijoeiro, nos dois sistemas de plantio. Também, estão ressaltadas as diferenças no custo de produção e, por conseguinte, no nível de receita ao produtor.

O fato de não terem sido observadas diferenças significativas entre os níveis de produtividade em função das doses de nitrogênio aplicadas é concordante com observações de ARF et al.(1999). Esses autores testaram doses de nitrogênio e formas de aplicação em cobertura, e seus efeitos na produtividade do feijoeiro e também não observaram efeitos das doses de N.

VIEIRA (1998a) ressalta que, para se obter alta produtividade na cultura do feijoeiro, são necessárias quantidades de $\mathrm{N}$ superiores a $100 \mathrm{~kg} \cdot \mathrm{ha}^{-1}$. No entanto, no presente trabalho, mesmo utilizando a dose de 100 kg.ha ${ }^{-1}$ de nitrogênio em cobertura, a produtividade máxima obtida foi de $1.640 \mathrm{~kg}$.ha ${ }^{-1}$, quando se aplicou $40 \mathrm{~kg} \cdot \mathrm{ha}^{-1}$ de $\mathrm{N}$ na forma de nitrato de amônio no plantio direto, e de $1.870 \mathrm{~kg} \cdot \mathrm{ha}^{-1}$ quando se utilizou uréia no plantio convencional. Ainda, segundo esse autor, em um total de 71 experimentos com nitrogênio em feijão, em $61 \%$ observou-se resposta positiva à aplicação do nitrogênio.
O nitrogênio promoveu incremento na produção com as duas fontes de $\mathrm{N}$ utilizadas, porém as diferenças não foram significativas, de modo que a análise econômica da prática é altamente justificável, pois a agricultura é uma atividade bastante dependente de custos e lucros.

Observações de Reıs et al. (1972) mostraram efeito similar dos fertilizantes nitrogenados uréia, fosfato de amônia, sulfato de amônio e salitre do chile na cultura do feijoeiro. No entanto, VIEIRA (1998b) revela que o aproveitamento das plantas em fertilizantes nitrogenados depende da forma do nitrogênio, do método de aplicação, das características físicas e químicas do solo, da freqüência e intensidade das chuvas, da presença de outro nutriente na formulação, dentre outros.

Durante o período chuvoso, as fontes de nitrato de amônio são, em geral, menos eficazes, principalmente em solos arenosos. Quando o solo é manejado no sistema de plantio direto e se faz uso de altas doses de nitrogênio, o efeito acidificante das fontes de nitrogênio deve ser considerado na escolha do fertilizante. Assim, é importante utilizar fontes diferentes em função da época e do local de semeadura, pois esses fatores podem influenciar na fixação do nitrogênio pela cultura e também no nível de produtividade.

Quadro 2. Acréscimo no custo, produção e na receita, nas diferentes fontes e doses de $\mathrm{N}$ utilizadas na cultura de inverno de feijão irrigado, em plantio convencional e plantio direto, em Pereira Barreto (SP), setembro de 2001

\begin{tabular}{|c|c|c|c|c|c|c|c|}
\hline \multirow{2}{*}{ Fonte } & \multirow{2}{*}{ Doses de $\mathrm{N}$} & \multicolumn{2}{|c|}{ Acréscimo no custo } & \multicolumn{2}{|c|}{ Acréscimo na produção } & \multicolumn{2}{|c|}{ Acréscimo na receita } \\
\hline & & P.C. & P.D. & P.C. & P.D. & P.C. & P.D. \\
\hline & kg.ha $a^{-1}$ & - & . & - & 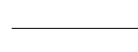 & & 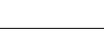 \\
\hline \multirow[t]{6}{*}{ Uréia } & 0 & - & - & - & - & - & - \\
\hline & 20 & 16,8 & 16,8 & 137,4 & 49,0 & 125,9 & 45,1 \\
\hline & 40 & 33,6 & 33,6 & 117,0 & 78,0 & 107,2 & 71,5 \\
\hline & 60 & 50,4 & 50,4 & 293,4 & 122,0 & 268,9 & 112,2 \\
\hline & 80 & 67,1 & 67,1 & 155,4 & 218,0 & 142,4 & 200,2 \\
\hline & 100 & 84,0 & 84,0 & 70,2 & 178,0 & 64,3 & 162,8 \\
\hline \multirow[t]{6}{*}{ Nitrato de amônio } & 0 & - & - & - & - & - & - \\
\hline & 20 & 19,8 & 19,8 & 96,0 & $-72,0$ & 88,0 & $-66,6$ \\
\hline & 40 & 39,9 & 39,9 & 126,0 & 349,8 & 115,5 & 320,6 \\
\hline & 60 & 59,7 & 59,7 & 264,0 & 117,0 & 24,2 & 162,2 \\
\hline & 80 & 79,6 & 79,6 & 128,4 & 145,2 & 117,7 & 133,1 \\
\hline & 100 & 99,6 & 99,6 & 247,8 & 316,2 & 227,1 & 289,8 \\
\hline
\end{tabular}

PC: Plantio convencional; PD: Plantio direto. 
Os resultados obtidos nas pesquisas, no entanto, evidenciam que esses fatos ainda não estão devidamente esclarecidos, principalmente quando se realiza a cultura no período seco, com irrigação. No tratamento com $20 \mathrm{~kg} \cdot \mathrm{ha}^{-1}$ de N, tendo como fonte o nitrato de amônio, obtiveram-se resultados negativos, uma vez que a produção foi inferior à da testemunha, fato de difícil explicação. Nos outros tratamentos, quando comparados à testemunha, observa-se aumento no lucro operacional.

O melhor resultado foi obtido no tratamento com $40 \mathrm{~kg} \cdot \mathrm{ha}^{-1}$ de $\mathrm{N}$ com nitrato de amônio, com $\mathrm{R} \$ 385,45 /$ ha e um índice de lucratividade, isto é, com participação do lucro operacional na receita bruta, de $25,6 \%$. No caso da uréia, os acréscimos nas dosagens de $\mathrm{N}$ foram compensatórios até a dose de $80 \mathrm{~kg}$.ha ${ }^{-1}$ de $\mathrm{N}$, e no de nitrato de amônio, o acréscimo nas quantidades de $\mathrm{N}$ (custos) não proporcionou acréscimos na produção (receitas) (Quadro 2).
As estimativas de produção, custos e lucratividade por hectare, em função dos tratamentos na cultura do feijoeiro, em plantio convencional, estão representados no quadro 1 . Observa-se que, com o uso de uréia como fonte de nitrogênio, obteve-se o melhor resultado na dose de $60 \mathrm{~kg} \cdot \mathrm{ha}^{-1}$ de N, com um lucro operacional de $\mathrm{R} \$ 696,60$ por hectare e um índice de lucratividade de $40,6 \%$.

Conforme os resultados obtidos com o uso de nitrato de amônio, observa-se que o maior lucro operacional de $\mathrm{R} \$ 586,80$, foi obtido com a dose de 100 kg.ha de N.

O índice de lucratividade, que representa a participação percentual do lucro operacional na receita bruta, é muito similar nas doses de 20, 40 e 100 kg.ha ${ }^{-1}$ de N (Quadro 1). Os resultados obtidos com o custo operacional total, receita bruta e lucro operacional para todos os tratamentos podem ser mais bem visualizados nas figuras 1, 2, 3 e 4 .

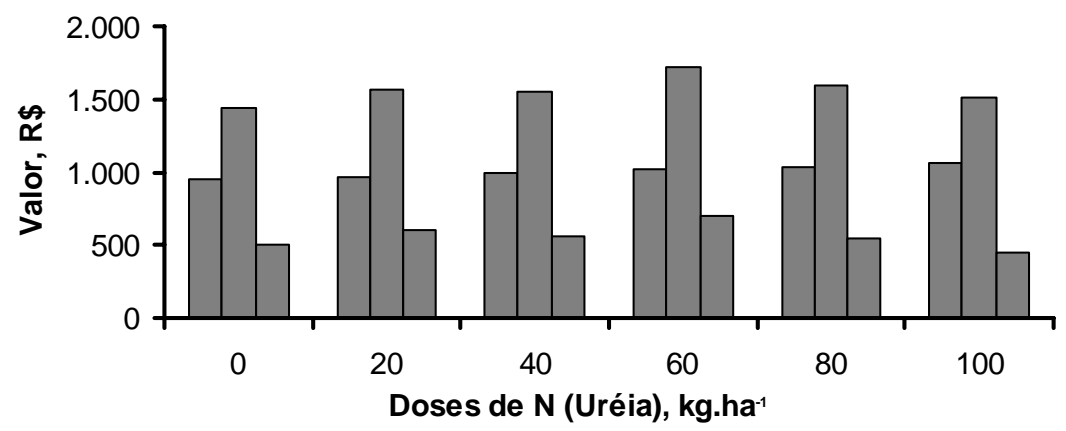

$\square$ custo de produção $\square$ receita bruta $\square$ lucro operacional

Figura 1.Custo de produção, receita bruta e lucro operacional para a cultura do feijoeiro, irrigado, no inverno, em plantio convencional, em Pereira Barreto (SP), setembro/2001.

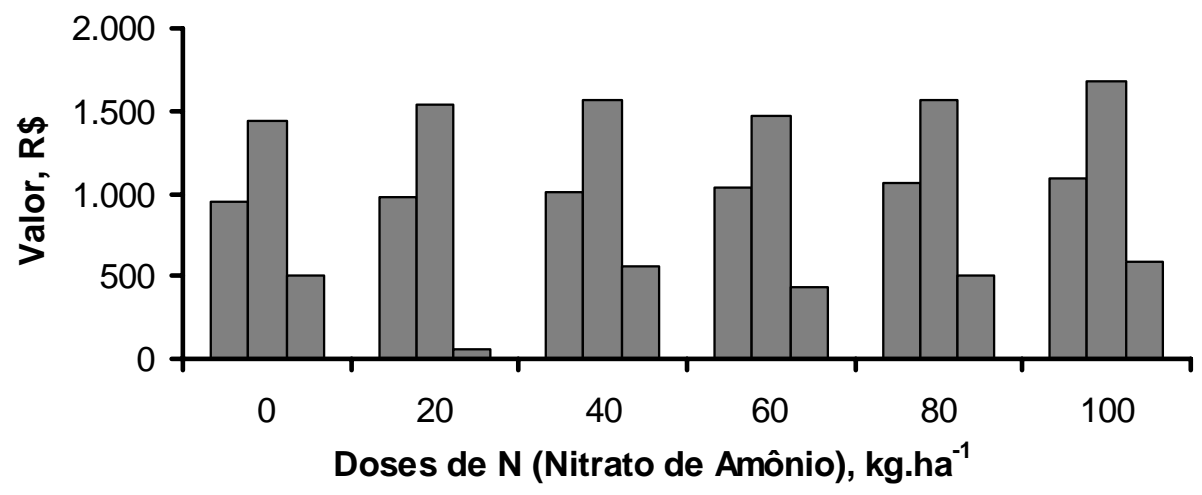

$\square$ custo de produção $\square$ receita bruta $\square$ lucro operacional

Figura 2. Custo de produção, receita bruta e lucro operacional para a cultura do feijoeiro, irrigado, no inverno, em plantio convencional, em Pereira Barreto (SP), setembro/2001. 


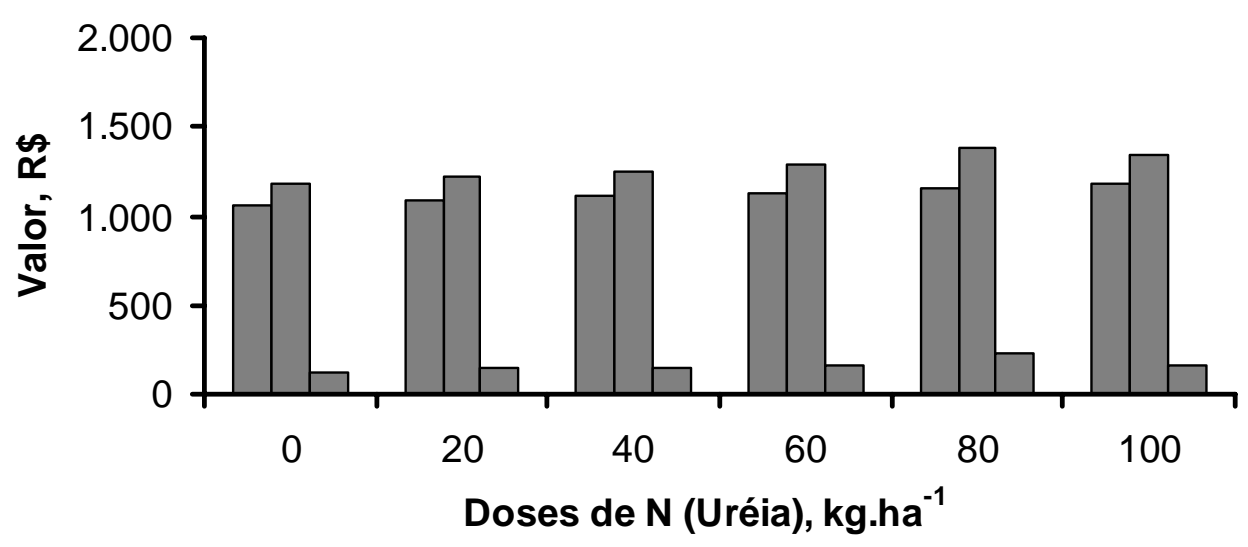

$\square$ custo de produção $\square$ receita bruta $\square$ lucro operacional

Figura 3. Custo de produção, receita bruta e lucro operacional para a cultura do feijoeiro irrigado, no inverno, em plantio direto, em Pereira Barreto (SP), setembro/2001.

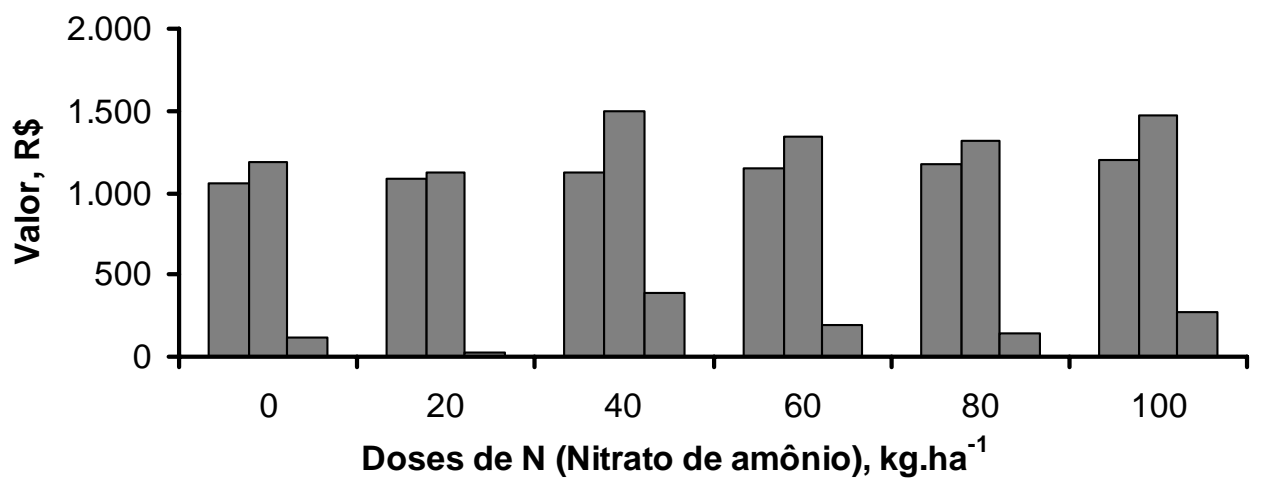

$\square$ custo de produção $\quad \square$ receita bruta $\quad \square$ lucro operacional

Figura 4. Custo de produto, receita bruta e lucro operacional para a cultura do feijoeiro irrigado, no inverno, em plantio direto, em Pereira Barreto (SP), setembro/2001.

\section{CONCLUSÕES}

Com apenas um ano de análise econômica na cultura do feijoeiro irrigado, em plantio de inverno, tem-se que:

1. Os melhores resultados financeiros são obtidos no sistema de plantio convencional.

2. Obtém-se o índice de lucratividade da ordem de 40,6\%, no sistema de plantio convencional com a aplicação de $60 \mathrm{~kg} \cdot \mathrm{ha}^{-1}$ de $\mathrm{N}$, em cobertura, com uréia como fonte.

3. O maior custo econômico no plantio direto, em relação ao convencional, está relacionado ao uso de herbicidas para o controle das plantas daninhas.
4. No plantio direto, o maior lucro foi obtido com o nitrato de amônio, na dose de $40 \mathrm{~kg} \cdot \mathrm{ha}^{-1}$ de N.

\section{REFERÊNCIAS BIBLIOGRÁFICAS}

ARF, O.; FERREIRA, E.C.; CARVALHO, M.A.C.; SÁ, M.E.; BUZETTI, S. Efeitos de doses e parcelamento da adubação nitrogenada em cobertura na cultura do feijão (Phaseolusvulgaris L.): In: REUNIÃO NACIONAL DE PESQUISA DE FEIJÃO, 6., 1999. Salvador. Resumos Expandidos... Santo Antonio de Goiás: EMBRAPA Arroz e Feijão, 1999. p.790-793.

BALBINO, L.C.; MOREIRA, J.A.A.; SILVA, J.G.; OLIVEIRA, E.F.; OLIVEIRA, I.P. Plantio direto. In: ARAÚJO, R.S.; RAVA, C.A.; STONE, L.F.; ZIMMERMANN, M.J.O. (Coords.). Cultura do feijoeiro comum no Brasil. Piracicaba: POTAFÓS, 1996. p.301-352. 
CONAB. Indicadores da Agropecuária. CONAB/MAA, Brasília-DF, ano X, nº 05, maio/2001, p.8 e 9.

KIYUNA, I. Mercado de feijão: preços em alta. Revista Preços Agrícolas, Piracicaba, ano XV, n 173, p.23, 2001.

MALAVOLTA, E. Leguminosas. In: Manual de calagem e adubação das principais culturas. São Paulo: Ceres, 1987. p. 112.

MATSUNAGA, M.; BEMELMANS, P.F.; TOLEDO, P.E.N.; DULLEY, R.D.; OKAWA, H.; PEDROSO, I.A. Metodologia de custo de produção utilizada pelo IEA. Agricultura em São Paulo, São Paulo, v.23, p.123-139, 1976.

NEHMI, I. M. D.; FERRAZ, J.V.; NEHMI FILHO, V.A; SILVA, M.L. (Coords.) AGRIANUAL 2000: Anuário Estatístico do Brasil. São Paulo: Argos Comunicações, 1999. p.507-520.
REIS, M.S.; VIEIRA, C.; BRAGA, J.M. Efeitos de fontes, doses e épocas de aplicação de adubos nitrogenados sobre a cultura do feijão (Phaseolus vulgaris L.). Revista Ceres, Viçosa, v. 19, n 1, p. 25-42, 1972.

VIEIRA, C. Adubação Mineral e Calagem. In: VIEIRA, C.; PAULA JUNIOR, T.J., BORÉM, A. (Eds.). Feijão: aspectos gerais e cultura no Estado de Minas. Viçosa: UFV, 1998a. p. 123-152.

VIEIRA, R.F. Quimigação e Fertirrigação. In: VIEIRA, C.; PAULA JUNIOR, T.J.; BORÉM, A. (Eds.). Feijão: aspectos gerais e cultura no Estado de Minas. Viçosa: UFV, 1998b. p.221-266. 